\title{
GAMES E APRENDIZAGENS NA PERSPECTIVA HISTÓRICO CULTURAL
}

\author{
Adriana Rocha Bruno \\ Janaina de Oliveira Nunes Ribeiro
}

Resumo

O presente artigo traz dados de uma pesquisa desenvolvida em nível de doutoramento. A investigação compreendeu como se dão os processos de ensino e de aprendizagem a partir da interação com jogos digitais, com base na teoria histórico cultural de Vigotsky e nos estudos clássicos sobre jogo, sociedade e educação, de Huizinga, Caillois e Brougère, e também nas perspectivas contemporâneas de pesquisadores que se debruçam a estudar as relações entre jogos digitais e educação. $\mathrm{Na}$ pesquisa de campo, jovens universitários experimentaram jogar dois newsgames e participaram de discussões dialógicas sobre os conceitos abordados nos games. A investigação conclui que os jogos digitais podem motivar os sujeitos para a formação de conceitos, aprendizagens e construções de conhecimento, por despertarem sentimentos, afetos, prazeres estéticos e desafios, sinalizando potencial para o campo da educação hodierna.

Palavras-chave: jogos e games digitais; ensino e aprendizagem; perspectiva histórico-cultural; educação e mediação partilhada.

\section{GAMES AND LEARNING IN THE CULTURAL HISTORICAL PERSPECTIVE}

\section{Abstract}

This article brings data from a research developed at the doctoral level and understood how the teaching and learning processes from the interaction with digital games take place, based on Vigotsky's historical cultural theory and classical studies on game, society and Education, by Huizinga, Caillois and Brougère, and also in the contemporary perspectives of researchers who study the relationship between digital games and education. In the field research, young college students tried to play two newsgames and participated in dialogical discussions about the concepts covered in the games. The investigation concludes that digital games can motivate the subjects for the formation of concepts, learning and knowledge constructions, by arousing feelings, affections, aesthetic pleasures and challenges, signaling potential for the field of today's education.

Keywords: games and digital games; teaching and learning; historical-cultural perspective; education and shared mediation.

\section{GAMES Y APRENDIZAJE EN LA PERSPECTIVA HISTÓRICA} CULTURAL

Resumen

Este artículo trae datos de una investigación desarrollada a nivel doctoral y entendió cómo se llevan a cabo los procesos de enseñanza y aprendizaje a partir de la interacción con los juegos digitales, basados en la teoría cultural histórica de Vigotsky y los estudios clásicos sobre juegos, sociedad y Educación, de Huizinga, Caillois y Brougère, y también en las perspectivas contemporáneas de los investigadores que estudian la relación entre los juegos digitales y la educación. En la investigación de campo, los jóvenes universitarios intentaron jugar dos newsgames y participaron en discusiones dialógicas sobre los conceptos cubiertos en los juegos. La investigación concluye que los juegos digitales pueden motivar a los sujetos para la formación de conceptos, aprendizajes y construcciones de conocimiento, al despertar sentimientos, afectos, placeres estéticos y desafíos, señalando el potencial para el campo de la educación actual.

Palabras clave: juegos y juegos digitales; enseñanza y aprendizaje; perspectiva histórico-cultural; educación y mediación compartida. 


\section{INTRODUÇÃO}

A aprendizagem baseada em jogos digitais é uma área de estudos recente, que vem sendo desenvolvida com base nas características dos games, no perfil dos jovens que cresceram imersos na cultura digital e, também, no desenvolvimento das neurociências, ou seja, em novas evidências científicas sobre como se dá a aprendizagem. No entanto, tomaremos como base nesse estudo sobre games e aprendizagem a psicologia social de Vigotsky, que aborda o desenvolvimento humano a partir de sua interação com o outro (mediação interpessoal), com instrumentos materiais e com instrumentos simbólicos ou signos. Acreditamos que a consistência de sua base teórica, lançada no início do século XX, pode ser aplicada ainda hoje, diante dos fluxos emergentes e das conexões expandidas nesse nosso ecossistema digital.

Desse modo, o objetivo desse artigo é compreender como se dão os processos de ensino e de aprendizagem a partir da interação com jogos digitais, com base na teoria histórico cultural de Vigotsky, nos estudos clássicos sobre jogo, sociedade e educação, de Huizinga (1938), Caillois (1994) e Brougère (1998), e também nas perspectivas contemporâneas de pesquisadores que se debruçam a estudar as relações entre jogos digitais e educação.

É claro que Vigotsky não tinha ideia das transformações sociais que hoje presenciamos com o desenvolvimento tecnológico, nem sequer pensava em gamificação. Mas, já naquela época, valorizava a brincadeira e os jogos como facilitadores do desenvolvimento. Ao falar de imaginação, criação e mediação semiótica, também nos ajuda a compreender como os novos símbolos culturais podem contribuir para a construção de sentido e o desenvolvimento das funções mentais superiores (linguagem, memória, atenção, sensação, percepção, emoção e sentimento), tão importantes para o processo de ensino-aprendizagem, tanto em crianças, quanto em jovens e adultos do século XXI.

Em um de seus escritos, de 1933, Vigotsky (2008) fala sobre o papel da brincadeira e dos jogos no desenvolvimento psíquico das crianças. $\mathrm{O}$ autor considera a brincadeira como imaginação em ação, ressaltando que a imaginação é uma forma especificamente humana de atividade da consciência. Aponta que brincando "[...] a criança aprende a agir em função do que tem em mente e não do que vê", ou seja, ela aprende a operar os significados, "[...] apoiando-se nas tendências e nos motivos internos, e não nos motivos e impulsos provenientes das coisas" (VIGOTSKY, 2008, p. 29). Ou seja, ao atuar em uma situação imaginária a partir de instrumentos concretos é possível desenvolver o pensamento abstrato e a construção de conceitos cotidianos e científicos. Os estudos de Vigotsky nos dão margem para pensar as possibilidades de desenvolvimento do adulto brincante ou jogador a partir da interação com os jogos digitais de hoje.

\section{JOGO, SOCIEDADE E EDUCAÇÃO}

Na primeira metade do século XX, Huizinga (2005) apontou que o fato de os meios de comunicação estarem estreitando as relações humanas fazia com que o elemento lúdico voltasse a se tornar mais presente na sociedade. Segundo o autor, os povos primitivos conviviam intensamente com elementos do jogo permeando aspectos da cultura. Ele observa que a partir do século XVIII, com a valorização da razão e da seriedade, em detrimento do lúdico e do jogo, o elemento lúdico da cultura entrou em decadência. Porém, a civilização não pode existir sem o lúdico, sem o espírito esportivo e a capacidade de fair play, entendida como a boa-fé expressa em termos lúdicos. De acordo com o autor, o jogo é uma função da vida e, também, uma vigorosa força criadora de cultura. 
Caillois (1994) considera a obra de Huizinga importante por romper com um ciclo de estudos que considerava os jogos apenas como simples diversões infantis, sem valor cultural, e também abrir caminhos à investigação e à reflexão sobre as relações entre o jogo e a cultura. Ele ressalta que o mérito do autor foi ter caracterizado os jogos e demonstrado sua importância para o desenvolvimento da civilização. No entanto, pondera que "[...] definir uma cultura unicamente a partir de seus jogos seria uma operação imprudente e provavelmente falaciosa"1 ${ }^{1}$ (CAILLOIS, 1994, p. 121). Mesmo assim, ressalta que a fertilidade cultural dos jogos pode revelar a identidade, o estilo e os valores de cada sociedade.

De acordo com Caillois (1994), são as disposições psicológicas que se manifestam e se desenvolvem a partir do jogo que se constituem como importantes fatores de civilização, não o jogo em si mesmo. Para ele cada tipo de jogo vai reforçar e aguçar determinada capacidade física ou intelectual, tornando prazeroso aquilo que em princípio poderia ser difícil e exaustivo. No entanto, ele é contrário à afirmação de que o jogo na infância seria uma aprendizagem para o trabalho adulto.

Brougère (1998) questiona se o fato de o jogo ser visto como algo não sério, muitas vezes fútil e frívolo pode ser resultado de um processo histórico de isolamento do jogo, de separação deste da vida social, sendo colocado à margem da realidade, da religião, do trabalho. Mesmo sendo considerado em sua frivolidade, para o autor, o jogo se constitui como um lugar de educação. Ele argumenta que há uma dialética complexa entre a aparente frivolidade e a função cultural do jogo, tendo o rito ou a recreação um importante lugar de formação cidadã.

Johnson (2005) explica que essa crítica negativa em relação aos games está fundamentada em um desconhecimento por parte das gerações mais velhas que ainda estão muito habituadas às formas de leitura tradicionais, como livros e jornais, e consideram que os videogames, e mesmo o cinema, a televisão e a internet, não são capazes de estimular as capacidades cognitivas que a leitura tradicional incentiva. Quando são julgados os benefícios dos videogames, eles ficam limitados ao desenvolvimento da coordenação visual e motora e o conteúdo é veemente criticado, classificado como violento e fantasioso. Ressalta que a contribuição cognitiva dos videogames não está diretamente relacionada ao conteúdo. O foco está no ato de jogar, ou melhor, no modo como você joga, estimulando o raciocínio, a rápida e eficiente tomada de decisões.

Seu argumento vai ao encontro das considerações de Paul Gee (2010) que afirma que mesmo sendo produtos da cultura popular, os games podem se constituir como um espaço para se "estudar e exercitar a mente humana" (2010, p. 210), desenvolvendo conceitos profundos e uma aprendizagem comprometida. Alves (2007) também ressalta a importância do ato de jogar, ao desenvolver a capacidade de aprender a aprender o que o programa é capaz de fazer, além de estimular a imaginação e o pensamento, ao trabalhar a simulação.

Todos esses argumentos nos servem de base para compreender como se dão os novos modos de aprendizagem influenciados pelas tecnologias digitais e, em especial, pelos videogames e jogos de computador. Somente a partir dessa compreensão é possível pensar nos modos de utilização desses recursos e nas estratégias de formações de professores para o uso dos games na educação. Afinal, como ressalta Alves (2008), é preciso que os professores se apropriem e lancem um novo olhar sobre esses recursos, indo além das perspectivas maniqueístas que só enxergam o lado negativo dos games, sem deixar de exercer uma leitura crítica dessas novas ferramentas comunicacionais.

\footnotetext{
1 Tradução livre para "[...] definir una cultura únicamente a partir de sus juegos sería una operación temeraria y probablemente falaz” (CAILLOIS, 1994, p. 121).
} 


\section{INSTRUMENTOS CULTURAIS E SIMBÓLICOS}

Para entender os newsgames como instrumentos simbólicos é importante conhecer o conceito de instrumento e signo para Vigotsky, bem como as relações entre a mediação semiótica, a linguagem e o desenvolvimento humano. Para o autor, o instrumento (ou ferramenta técnica) é orientado externamente, utilizado como um "condutor da influência humana sobre o objeto da atividade", ou seja, é dirigido "para o controle e domínio da natureza". O signo, por outro lado, "constitui um meio da atividade interna dirigido para o controle do próprio indivíduo". Desse modo, "o controle da natureza e o controle do comportamento humano estão mutuamente ligados, assim como a alteração provocada pelo homem sobre a natureza altera a própria natureza do homem" (VIGOTSKY, 2007, p. 55). Em outras palavras, ele considera que da mesma forma com que o homem usa o instrumento técnico para modificar a natureza e suas relações externas com o mundo, utiliza-se também dos signos (ou instrumentos simbólicos) para modificar internamente suas próprias atividades mentais e sociais.

Portanto, instrumentos e signos são para Vigotsky os dois tipos de mediadores utilizados para regular nossas ações. Por um lado, os instrumentos ou ferramentas técnicas conferem à atividade humana sua especificidade criadora, revelando o nível de desenvolvimento cultural do homem. Por outro, os signos ou instrumentos simbólicos atuam como mediadores na formação da consciência, como elementos usados para transformar as funções mentais elementares (naturais e biológicas, que dependem apenas de estruturas orgânicas, como os atos reflexos e a atenção involuntária) em funções mentais superiores (de origem sociocultural, tais como memória, imaginação, pensamento e linguagem etc.).

Dessa forma, ao compreender os newssgames como instrumentos simbólicos, pressupomos que o conhecimento que pode ser desenvolvido pelos sujeitos jogadores a partir de suas interações com esses games vai depender de sua mediação com os elementos, a interface e a experiência do jogo, bem como do contexto sócio histórico e cultural em que ele vive e das interações pessoais que ele desenvolve.

\section{CONCEITOS ESPONTÂNEOS E CONCEITOS CIENTÍFICOS}

Ao se referir aos conceitos científicos, Vigotsky (2007) fala da importância da instituição escolar e da intervenção pedagógica para o desenvolvimento dos indivíduos nas sociedades letradas. Segundo ele, os processos de ensino e de aprendizagem promovidos pela interação com um outro mais experiente, no ambiente escolar, desperta processos internos de desenvolvimento. Diferentemente dos conceitos cotidianos, eles são organizados em sistemas consistentes de interrelações e envolvem uma atitude mediada para sua construção.

Vigotsky afirma que "em qualquer idade, um conceito expresso por uma palavra representa uma generalização" (2009, p. 246), ressaltando que tais conceitos estão sempre sujeitos a mudanças, pois evoluem, assim como acontece com o significado das palavras em diferentes épocas ou contextos culturais. O autor defende que "a apreensão do sistema de conhecimentos científicos pressupõe um tecido conceitual já amplamente elaborado e desenvolvido por meio da atividade espontânea do pensamento infantil”' (2009, p. 269).

Esse tecido conceitual vai sendo construído ao longo do desenvolvimento do indivíduo a partir de sua interação com instrumentos e símbolos e também da interação com outros indivíduos em suas atividades no dia a dia. É um tipo de conhecimento cotidiano e espontâneo, importante 
para a sobrevivência (que nos leva a conhecer os perigos do mundo ao nosso redor, por exemplo) e a para a sociabilização, pois nos capacita para a vida em sociedade.

Os conceitos espontâneos, segundo Vigotsky (2009), são aqueles formados a partir de situações concretas vividas no cotidiano, que sofrem influência dos científicos, mais elaborados, devido ao constante processo de interação entre ambos. Ou seja, os conceitos científicos superiores surgem a partir de generalizações elementares inferiores pré-existentes (conceitos espontâneos), não podendo ser inseridos de fora na consciência dos sujeitos. Demandam um processo de internalização, que vai depender da mediação semiótica com signos e instrumentos.

Ao entender os jogos digitais, e especificamente os newsgames, como uma mídia veiculadora de informações, a tendência neste texto é aproximar o tipo de conhecimento neles contidos com os conceitos espontâneos ou cotidianos. Afinal, o próprio Robert $\operatorname{Park}^{2}$ (2008) considerava as notícias como uma forma elementar de conhecimento, estando entre a familiaridade com as coisas e o conhecimento das coisas. Concepção que se assemelha à de Vigotsky em relação aos conceitos espontâneos. Mas, os resultados da análise do trabalho de campo apontam que a interação com e entre os sujeitos nas discussões em grupo e as indexações realizadas pelos jogadores, relacionando os jogos com outros conteúdos já armazenados em suas mentes, fazem com que os conceitos científicos comecem a se revelar.

Interessa-nos pensar na importância das relações entre conceitos espontâneos e científicos para a construção de sentidos por parte dos sujeitos jogadores que participaram desta pesquisa. Vygotsky (2009) afirma que quanto mais conceitos espontâneos o indivíduo carrega em sua bagagem, maiores são as possibilidades de relações que podem ser feitas para a construção de conceitos científicos. Então, a tarefa realizada durante a análise do trabalho de campo foi compreender no texto e no contexto do discurso dos sujeitos quais os sentidos construídos por eles e que formações conceituais puderam se desenvolver a partir da interação com os newssgames, com os demais sujeitos e com suas próprias indexações de memória.

\section{BREVE DESCRIÇÃO DOS NEWSGAMESJOGADOS NA PESQUISA}

“O combate do Barro Vermelho", criado pela equipe do jornal Zero Hora, em 2011, aborda uma temática histórica, a Revolução Farroupilha, ocorrida no século XIX no Sul do Brasil. O jogo é inspirado em uma das principais vitórias farroupilhas da década da revolução (1835-1845). Travado na então vila do Rio Pardo, hoje município de mesmo nome, o confronto ocorreu em 30 de abril de 1838. Na época, Rio Pardo representava um dos principais centros urbanos da Província de São Pedro do Rio Grande do Sul.

Possui uma jogabilidade bem desenvolvida e se apresenta com um roteiro clássico, que envolve começo, meio e fim. As instruções de como jogar e as informações históricas sobre o confronto do Barro Vermelho e sobre a Revolução Farroupilha são apresentadas antes do início do jogo, sendo possível pular algumas informações e ir direto para o jogo. São várias as telas que o usuário precisa percorrer para ler todas as instruções e informações. Na tela inicial, ao clicar em instruções, abre-se a segunda tela do jogo:

\footnotetext{
${ }^{2}$ O sociólogo Robert Park é considerado como o primeiro intelectual a compreender as notícias como uma forma de conhecimento.
} 
Figura 1. Tela de instruções sobre o objetivo do jogo $\mathbf{O}$ combate do Barro Vermelho

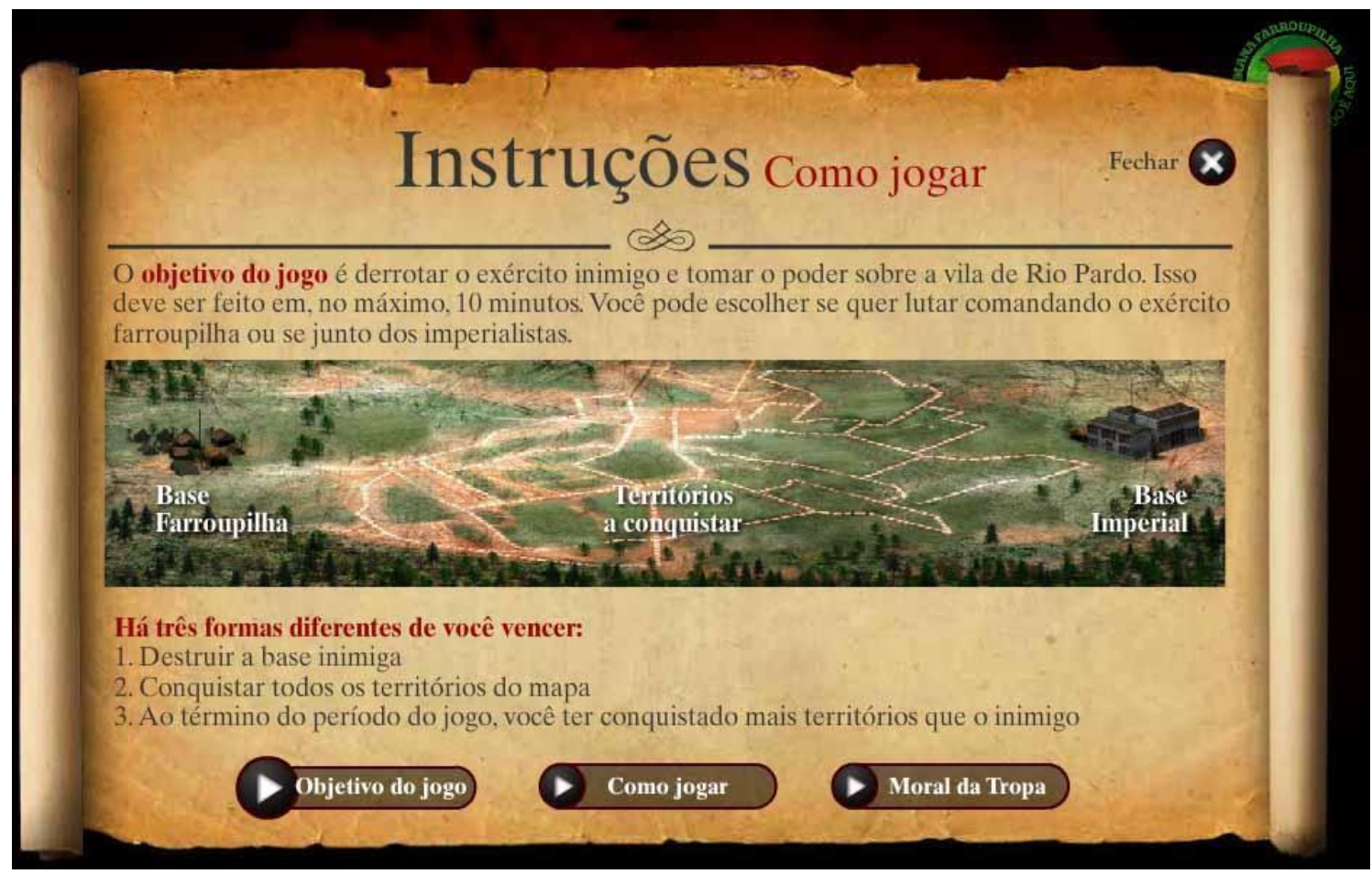

Fonte: http://www.clicrbs.com.br/swf/game_farroupilha/index.html

Nesta tela (Figura 1) são apresentados o objetivo do jogo e as diferentes formas de se vencer a batalha (texto da Figura 1). Há ainda a informação de que o jogo tem duração de 10 minutos e de que é possível escolher com qual exército se deseja jogar, farroupilha ou imperialista. A partir dessa tela, o jogador pode seguir para saber mais sobre as instruções do jogo, clicando em "Como jogar" e em "Moral da Tropa", ou pode simplesmente fechar a tela, clicando no "X" disposto no canto superior direito, e partir para o jogo. As informações contidas no link "Como jogar" explicam quais são as tropas disponíveis e dá algumas dicas para se começar o jogo: enviar tropas logo no início ou esperar alguns segundos para levantar a moral do batalhão e ter mais opções de tropas para enviar.

É importante ressaltar que durante todo o jogo, é possível esquecer que se trata de uma simulação sobre a Revolução Farroupilha. Como as informações são dadas somente antes do início da batalha, com opção de pular e partir direto para o jogo, durante o processo de jogabilidade, o sujeito deve se concentrar apenas em enviar as tropas em uma ordem e um tempo que possam garantir a vitória. Poderia se tratar de uma batalha qualquer, pois a referência ao fato histórico nesse momento é irrelevante para o sucesso ou derrota do jogador.

No entanto, vale notar que, nas mensagens de finalização do jogo, há informações que se forem lidas podem reforçar o conhecimento histórico sobre a Revolução Farroupilha. Ao repetir nomes de personagens, nomes de localidades e lembrar ao jogador que se trata de uma batalha que na realidade foi vencida pelos farroupilhas (mesmo que na ficção do jogo você tenha vencido com o exército imperialista), a mensagem final pode atuar como um recurso de memorização das informações iniciais. 
"A cobra vai fumar" 3, desenvolvido em abril de 2011 e publicado na Revista Superinteressante Digital, mostra a ação dos pracinhas brasileiros na Segunda Guerra Mundial. De acordo com Fred Di Giacomo, responsável pela criação e roteiro do jogo, as situações nele apresentadas são baseadas em relatos reais de pracinhas que deram entrevistas para reportagens das revistas Superinteressante e Aventuras na História, ambas da Editora Abril. No blog da revista, ele contou que esta foi uma das produções mais trabalhosas da equipe, consumindo três meses de trabalho para sua conclusão. "O resultado foi um game mais focado para hevay users (usuários mais experientes) e menos para o internauta usual", afirmou Giacomo, ressaltando ter seguido o "estilo 'point and click' de clássicos como Full Throttle e Day of the Tentacle" (GIACOMO, 2011).

Figura 2. Tela inicial do newsgame A cobra vai fumar

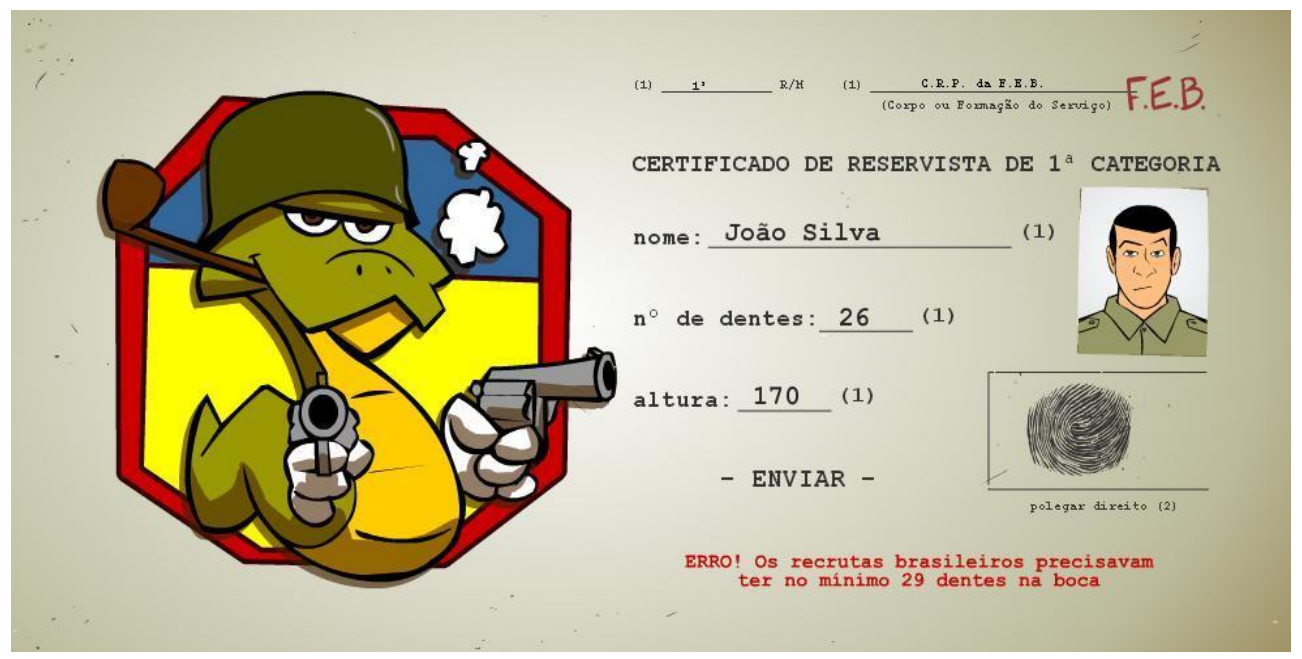

Fonte: Super Interessante Digital, 2011. Acesso indisponível.

$\mathrm{Na}$ tela inicial você pode optar por ver a introdução ou partir direto para o jogo. Clicando em Introdução, aparece uma sequência de slides com fotos de soldados em guerra e informações históricas sobre o combate ${ }^{4}$. Ao clicar em jogar, é preciso se inscrever/alistar como um soldado, preenchendo uma ficha com seus dados. Nessa parte há uma "pegadinha informativa", pois na época do recrutamento para a Segunda Guerra Mundial só eram aceitos jovens que tivessem no mínimo 29 dentes na boca e com altura mínima de 155 centímetros. Dessa forma, no jogo, se os campos " $\mathrm{n}$ " de dentes" $\mathrm{e}$ "altura" forem preenchidos com valores inferiores, a inscrição é recusada e aparece essa justificativa quanto à altura mínima e número de dentes.

Ao iniciar, o jogador assume o papel de um pracinha brasileiro e durante o andamento das fases do jogo vai enfrentando situações adversas em que precisa se adaptar, passar por treinamento, compreender as orientações e sobreviver. $\mathrm{Na}$ primeira etapa, o pracinha/jogador é treinado por

\footnotetext{
${ }^{3}$ Devido a uma mudança na plataforma do site da Revista Superinteressante, o acesso ao jogo, atualmente, encontrase indisponível.

4 Transcrição das informações dos slides: " 25.334 brasileiros compuseram a FEB; 49 pilotos foram enviados pela FAB; 455 brasileiros morreram durante a guerra na Itália; 239 dias foi o tempo de engajamento em combate da divisão brasileira na Itália; 15.000 soldados alemães da $148^{\circ}$ Divisão da Infantaria alemã, incluindo dois generais, foram capturados pelo exército brasileiro em 3 dias. Na época, a piada que rolava no Brasil é que seria mais fácil uma cobra fumar que o país enviar soldados para o combate... mas a cobra fumou".
} 
um sargento americano, mas ele não entende o idioma de seu superior. As "conversas" (em caixas de texto) aparecem cifradas e o jogador precisa descobrir o que é preciso fazer para avançar.

De acordo com as instruções, o jogador deve clicar na boca para conversar, na mão para pegar e na bota para chutar. Ao tentar conversar com o sargento Norris, é preciso decifrar o que ele diz (as instruções vêm em caixa de texto, mas como ele fala uma língua estranha à do soldado, as palavras vêm cifradas, em código). Os objetos estão no cenário e as instruções não são claras, mas aos poucos (depois de algumas tentativas e erros), é possível perceber o que é preciso fazer. Quando o jogador consegue executar as primeiras ações, aparece uma nova mensagem no rodapé do cenário: "Muito bem! Os soldados brasileiros sofreram com o inverno de 1945, o mínimo que você precisa para ficar aquecido são duas meias e as botas. Agora tente entender o que o sargento Norris está dizendo". Essa informação é importante, pois contextualiza as situações que vão aparecer nas próximas fases do jogo, mas também ajudam a compreender um pouco da experiência vivida pelos pracinhas: eles precisavam decifrar as ordens dadas pelo superior e se preparar para enfrentar o frio europeu.

$\mathrm{Na}$ próxima "fala" do sargento, entre códigos é possível compreender as palavras rifle e alvo. Por intuição, é preciso descobrir que a ordem é para pagar pegar o rifle e treinar tiro ao alvo. Ao executar essas ações, aparece uma tela preta com a seguinte mensagem: "Hora de mostrar que os pracinhas são bons de mira. Acerte os 3 alvos ou você terá que recomeçar o treinamento". O soldado tem sete munições para acertar os três alvos que estão em diferentes distâncias, se não conseguir retorna à etapa anterior e precisa reiniciar a conversa com o sargento. Somente após conseguir o feito ele pode avançar.

A etapa seguinte começa com mais um slide informativo, na mesma estética das informações iniciais. O trecho do depoimento de um ex-combatente passa a ideia do frio enfrentado pelos soldados durante a guerra, reforçando mais uma vez que a experiência dos pracinhas durante o inverno europeu não foi nada fácil.

Esta fase do jogo se inicia no cenário de gelo e neve. O jogador encontra um colega soldado que está sentado lendo jornal. Do seu lado direito há meias, do lado esquerdo um monte de feno com um cachorro dormindo em cima. Atrás, uma barraca de acampamento. E no meio da cena uma pá fincada no solo coberto de neve. A mensagem inicial diz o seguinte: "Os pracinhas tiveram que aguardar o fim do inverno para tentar tomar a montanha controlada pelos alemães. Você precisa ficar aquecido, e evitar uma temida doença do frio, o 'pé de trincheira"'.

Com essas informações, o jogador percebe que precisa buscar formas de se proteger do frio e que a consequência da falta de proteção é uma doença que atinge os pés. Nas próximas fases são apresentados outros desafios enfrentados pelos pracinhas durante a Segunda Guerra. Apesar de "A cobra vai fumar" trazer sim informações apresentadas nas telas de introdução, antes do jogo, como depoimentos e dados numéricos sobre a participação dos brasileiros na Segunda Guerra (número de soldados, número de mortos, quantos dias durou o combate), há muitas informações que aparecem interconectadas às cenas, nas situações, na jogabilidade. Isso faz com que o jogador possa não apenas conhecer, no sentido de ter contato com as informações, mas também experimentar, vivenciar situações, o que Bogost (2007) chama de retórica processual do jogo, ou seja, a capacidade de construir ideias a partir de uma simulação computacional.

Com esse newssgame é possível, então, construir conhecimentos sobre a experiência dos pracinhas na Segunda Guerra Mundial, dando sentidos próprios à relação que eles tiveram com as adversidades do combate, como o frio, o idioma estrangeiro, o ambiente hostil, o medo. Tudo isso, de forma divertida e lúdica, afinal, a linguagem é de jogo digital, com uma estética de animação colorida e o uso de verbetes criativos e até engraçados. 


\section{A CONSTRUÇÃO DE CONHECIMENTO A PARTIR DOS NEWSGAMES}

Durante os encontros com os sujeitos ${ }^{5}$ a dinâmica metodológica consistia em convidá-los a experimentar um newsgame a cada semana, determinando um tempo para a jogabilidade, e em seguida deixar que falassem livremente sobre suas impressões acerca do jogo. No próximo encontro, a discussão dialógica era mais direcionada para as possibilidades de construção conceitual a partir do jogo experimentado na semana anterior, estabelecendo uma mediação partilhada (BRUNO, 2007), em que a docente pesquisadora se colocava em posição horizontal diante dos alunos partilhando e participado com eles da discussão. A intenção era verificar o que havia ficado na memória, contando que nesse intervalo de tempo o sujeito poderia ter pensado sobre o jogo, comentado com outras pessoas, jogado novamente caso desejasse. Desse modo, a pesquisadora e mediadora do debate colocava questões acerca de alguns conceitos contidos na narrativa do newssgame ou na temática abordada e participava com eles da elaboração das respostas.

Por exemplo, na discussão conceitual acerca do newsgame "O combate do Barro Vermelho" 6 refletimos sobre a história da Revolta Farroupilha e sobre o conceito de estratégia que permeia o jogo. Publicado em setembro de 2011, no site do jornal Zero Hora, a narrativa aborda o combate na vila de Rio Pardo, ocorrido durante a Revolta Farroupilha, entre 1835 a 1845, no Sul do Brasil. O objetivo é conquistar territórios no mapa enviando soldados em direção à base inimiga. Cada tropa equivale a uma determinada pontuação, e o jogador precisar acumular pontos para prosseguir enviando tropas e permanecer no jogo. Vence quem conquistar mais territórios num prazo de dez minutos.

Na discussão logo após o jogo, a grande questão havia sido a falta de relação entre a história e a jogabilidade. Mesmo lendo as instruções iniciais do jogo, com informações históricas sobre a Revolta Farroupilha, os sujeitos comentaram que os dados não ficam na memória, pois não são necessários para se entender e vencer o jogo. Se dar bem nesse game é uma questão de estratégia, de saber que tropas enviar em qual momento. $\mathrm{Na}$ semana seguinte, foi pedido que tentassem explicar o que sabiam sobre a Revolta Farroupilha, verificando se haviam memorizado alguma informação transmitida pelo newsgame. Após segundos de silêncio, o estudante de filosofia citou a minissérie A Casa das Sete Mulheres, exibida pela Rede Globo em 2003. Todos disseram que ao pensar em Revolta Farroupilha, a primeira recordação era A Casa das Sete Mulheres.

Dois dos estudantes de jornalismo disseram ter pulado as informações históricas que apareciam nas telas iniciais para ir direto para o jogo, pensando que em algum momento poderiam voltar para ler, caso julgassem necessário. Mas, como não foi preciso, seguiram enviando tropas e conquistando territórios sem ler nada sobre a história do combate entre imperialistas e farroupilhas. Mesmo os que leram as informações, não demonstraram ter assimilado os textos desse newsgame como geradores de conhecimento. Para Bakhtin (1993), o que leva ao conhecimento é a palavra internamente persuasiva, ou seja, aquela que se entrelaça com a "nossa palavra" formando novos significados. E o que aconteceria se as informações pudessem ser assimiladas junto com a simulação da batalha; os sujeitos experimentariam o conteúdo como uma vivência pessoal, possibilitando novas significações.

Ao refletir sobre as estratégias utilizadas por eles, os sujeitos entenderam que conhecer as funções militares poderia ajudar a conquistar o território inimigo e vencer o jogo. Pensar na

\footnotetext{
${ }^{5}$ Ao todo participaram dos encontros quatro estudantes de Jornalismo, três estudantes de Licenciatura em História e um estudante de Licenciatura em Filosofia. Todos da Universidade Federal de Juiz de Fora.

${ }^{6}$ Disponível em: http://www.clicrbs.com.br/swf/game farroupilha/index.html. Acesso em: 10 de dezembro de 2019.
} 
velocidade e alcance da tropa exige habilidades de concentração, raciocínio e tomada de decisão. Mas, para isso, é preciso interpretar qual a função de cada tropa, qual delas pode ser utilizada como escudo, qual o melhor momento de enviar a artilharia, a cavalaria, o canhão ou ativar a banda de música para elevar a moral.

Percebe-se, nesses discursos, que a compreensão ativa para a construção de conhecimento passa pela indexação de informações vindas de outros contextos, como uma "cadeia de criatividade e compreensão ideológicas, deslocando-se de signo em signo para um novo signo" (BAKHTIN/VOLOCHÍNOV, 2009, p. 34), de maneira única e contínua, realizada a partir da interação entre os sujeitos. Afinal, mesmo aqueles que não leram as informações ou que, a princípio, achavam que vencer não era questão de estratégia, mas sim de sorte, puderam ressignificar suas considerações a partir das colocações dos outros.

Em geral, a questão crítica desse newsgame é o fraco sentimento de imersão. O jogador não assume o papel de um personagem presente na cena do jogo, precisa apenas entender como a sequência de comandos pode levar à vitória. A narrativa sobre a Revolta Farroupilha não está conectada às ações do jogo, o discurso parece autoritário e não persuasivo, dificultando a compreensão ativa do tema. Mesmo assim, optei por colocá-lo no rol de newsgames a serem trabalhados no campo dessa pesquisa, pois considero que a comparação deste com o próximo pode gerar dados interessantes.

No newssgame "A cobra vai fumar", apresentado anteriormente, é preciso compreender as ordens do sargento americano, treinar tiro ao alvo, cavar um buraco para se esconder e sobreviver ao inverno europeu, encontrar o fio partido de um rádio comunicador que se encontra em solo inimigo e religar o aparelho.

Atuar como um avatar proporciona o que Santaella e Feitosa (2009) chamam de imersão representativa, que seria o tipo de imersão mais comum entre os jogos digitais, fazendo com o jogador sinta-se representado no ambiente virtual, vivenciando as situações e vendo o resultado de suas ações. Isso faz com que o jogador possa experimentar situações, desenvolvendo o que Bogost (2007) chama de retórica processual do jogo, ou seja, a capacidade de construir ideias a partir de uma simulação computacional.

Durante a livre discussão, os estudantes comentaram sobre a sensação de sentir um pouco do que os soldados viveram, ressaltando que o jogo serviu como um despertar de interesse para saber mais sobre a história. Também comentaram sobre as dificuldades de decifrar a jogabilidade, descobrir o que era preciso ser feito para avançar nas etapas. Um dos estudantes de história ressaltou que, para ele, esse sentimento de estar perdido, sem saber como jogar, pode ter sido o sentimento dos pracinhas em um local hostil, estrangeiro, sem conhecer a língua, sem saber o que fazer, por onde começar. No entanto, um dos estudantes de jornalismo apontou que muitas das informações que aparecem nos slides da introdução e entre as fases do jogo não ficam retidas na memória, principalmente quando se referem a números relacionados à guerra (número de brasileiros na expedição, número de mortos, número de alemães capturados, quantidade de dias de duração do conflito).

De acordo com Arruda (2009), mesmo que os sujeitos não memorizem detalhes do fato histórico e mesmo que não consigam aprender história a partir dos games, o que se destaca nessa interação é o desenvolvimento do raciocínio histórico. Ele ressalta que a construção narrativa dos jogadores, a partir dessa imersão, da sensação de entrar nos cenários históricos e, de alguma forma, fazer parte daquele contexto é o que leva ao desenvolvimento da capacidade de pensar

\footnotetext{
${ }^{7}$ Disponível em http://super.abril.com.br/multimidia/info 510704.shtml
} 
historicamente e "compreender a História como construção, como um passado visto do presente, reflexo de quem escreve em uma determinada época" (2009, p. 169).

Durante a discussão conceitual, foi pedido que fizessem o exercício de lembrar o que sabiam sobre a história da atuação brasileira na Segunda Guerra Mundial antes de jogar e o que aprenderam com o jogo. Os diálogos foram aos poucos envolvendo as outras formações conceituais que eu havia selecionado para a discussão, como a vivência dos pracinhas no cotidiano da guerra e a questão da sobrevivência em um ambiente hostil. Em geral, pode-se perceber que a interação com o newssgame levou os sujeitos a apreenderem conhecimentos mais relacionados ao cotidiano da guerra.

No entanto, eles seguiram a discussão relacionando as experiências no jogo com conhecimentos adquiridos em disciplinas do Ensino Médio e da Faculdade de História, bem como com experiência de amigos e conhecidos que integram o Exército Brasileiro. Ao trabalhar com indexações de memória relacionadas a um conhecimento mais crítico e aprofundado, desenvolvido no ambiente universitário, uma das estudantes de história pode ter contribuído para a reflexão dos outros sujeitos. Mas, mesmo que nem todos tenham conseguido compreender em profundidade o contexto histórico nacional no momento da participação dos pracinhas na Segunda Guerra Mundial explicado pela estudante, ela o fez ao inter-relacionar os saberes que já possuía com os apreendidos a partir da interação dialógica com o newssgame e da mediação partilhada com grupo de sujeitos da pesquisa.

A discussão percorreu vários caminhos, sendo que, por vezes não estávamos falando especificamente do newsgame. Em muitos momentos, este era apenas o ponto de partida e de encontro dos discursos, que demonstravam construções de sentido inter-relacionando signos do jogo, dos diálogos entre os sujeitos e das indexações de memória. Por fim os conceitos apontados no roteiro de observação utilizado na pesquisa foram discutidos, mas outros tantos se desenvolveram a partir do diálogo, tanto em relação aos conhecimentos do cotidiano da guerra quanto no que diz respeitos a conhecimentos mais elaborados em relação ao contexto histórico e político. Também construímos um pensamento crítico sobre as influências desse passado histórico na cultura dos brasileiros, sobre como interpretamos essas influências e como nos reconhecemos enquanto nação.

\section{CONSIDERAÇÕES FINAIS}

Não jogamos pensando em aprender, jogamos para nos entreter, nos divertir. Coube à pesquisadora, e uma das autoras deste texto, mediar as discussões para que os sujeitos pudessem pensar no potencial de cada newsgame para a construção de conhecimento. Fazer com que o excedente de visão ao longo da investigação os ajudasse a enxergar o que estavam aprendendo. Por mais que se possa aprender na interação com um game, nada se compara às possibilidades de construção de sentido a partir da interação com os outros sujeitos após o jogo. Ao falar sobre a experiência do jogo, desenvolvemos nosso pensamento para traduzir em palavras nosso discurso interior. De acordo com Bakhtin, a palavra é o primeiro meio da consciência individual, é o material semiótico do discurso interior e "está presente em todos os atos de compreensão e em todos os atos de interpretação" (2009, p. 38).

Vigotsky (2007) nos fala sobre a mediação do sujeito com o mundo, que tem nos dispositivos os instrumentos e/ou os signos, sejam eles objetos ou elementos culturais, a linguagem e o outro, como intermediadores em relação. Para Bruno (2007) a mediação pedagógica tem o objetivo de promover, por meio de encontros entre docentes e discentes, a aprendizagem. Trata- 
se de uma ação que se faz por meio da partilha e da interatividade entre os sujeitos nos processos de ensino e de aprendizagem.

$\mathrm{Na}$ pesquisa em questão (RIBEIRO, 2016), a relação cocriada entre os sujeitos e a pesquisadora se deu por meio do que Bruno (2007) chamou de mediação partilhada. A partilha se dá por meio da relação de parceria, de entrega e imersão de todos os que estão implicados na pesquisa. Não há hierarquia, mas colaboração. Nesta direção, a mediação partilhada ocorre com a produção de devires, de olhares, de percepções, do ser e do estar juntos nas emergências daquele encontro, daquela acontecência. Tal processo é possível desde que existam interagentes que desejem ali estar e compor, por meio da partilha, seus saberes, suas ações nas práticas culturais e na produção coletiva de conhecimentos em ambiências formativas.

Vale ressaltar a importância do lúdico para a aprendizagem, e com bases nas experiências deste trabalho consideramos que os jogos digitais podem motivar os sujeitos para a formação de conceitos, aprendizagens e construções de conhecimento, por despertarem sentimentos, afetos, prazeres estéticos e desafios.

No campo da comunicação, como material jornalístico, são instrumentos culturais e simbólicos que podem fazer diferença na formação cidadã, pelo potencial reflexivo de seus argumentos narrativos e por sua retórica procedimental. No campo da História, podemos considerar como conhecimento científico a compreensão do fato histórico envolvendo o contexto, o acontecimento e suas consequências, relacionando passado, presente e futuro.

Dessa forma, acreditamos que a simples experiência vivenciada nesses jogos digitais possa contribuir de modo especial para a formação de conhecimentos cotidianos, conforme definidos por Vigotsky (2009). No entanto, com base nas análises das falas dos estudantes, evidenciam-se que também foram construídos conhecimentos científicos a partir da mediação simbólica dos jogos somada às trocas interpessoais e dialógicas estabelecidas entre os sujeitos, que aprofundaram a discussão acerca do contexto histórico, ora compartilhando conhecimentos científicos elaborados em seus ambientes de ensino e de aprendizagem, ora desenvolvendo generalizações conceituais acerca de informações e sentimentos relacionados à temática dos newsgames experimentados.

A partir das discussões dialógicas foi possível ir muito além, desenvolvendo construções conceituais, abstrações e generalizações. Isso porque se estabeleceu entre os diferentes sujeitos em diálogo o que Vigotsky chama de zona de desenvolvimento proximal/potencial (ZDP), quando estes compartilham suas aprendizagens e colaboram para o desenvolvimento dos demais, numa relação de trocas efetivas e mútuas (VIGOTSKY, 2007).

No campo da educação, compreendemos que jogos como estes possam ser trabalhados de forma complementar a outros materiais mais ricos em informações, contextualizações e conceitos. Mas, ainda mais do que complemento, os jogos e games podem promover formas de pensamento, de articulação de ideias e de afetos que trazem outros modos de aprender e, por conseguinte, outras formas de ensinar. A relação com o outro por meio de games tem sinalizado a promoção de horizontalidades, de partilhas, de colaboração. Por meio de mediação partilhada (BRUNO, 2007), o mediador que se assume como parceiro do/a estudante, atua como disparador e instigador da criação de campos em que a ZDP aconteça. As mudanças nas ambiências, nas relações, nas concepções são potencializadas com os jogos e games digitais. Dessa forma, reafirmamos que os newsgames, assim como outros tipos de jogos digitais e videogames, podem sim ser considerados como espaços de aprendizagem, mas esse potencial tende a se ampliar com uma discussão mediada, uma mediação partilhada, pós-jogo ou mesmo ao longo do jogo.

De acordo com Linderoth (2009), não se pode apontar os efeitos de um jogo, pois estes variam em função dos usos, dos contextos e dos sistemas sociais construídos à sua volta. 
Entretanto, com base na experiência desses encontros, é válido ressaltar que o potencial para o desenvolvimento de aprendizagens a partir de newsgames também pode aumentar quando os elementos informativos e narrativos são interligados à jogabilidade, pois os prazeres estéticos de agência, imersão e transformação (MURRAY, 2003) contribuem para o processo de construção de conhecimento, à medida que despertam emoções nos sujeitos. Mesmo partindo do pressuposto de que qualquer jogo pode ensinar alguma coisa, jogos esteticamente bem desenvolvidos são considerados como bons jogos que podem ampliar o potencial para boas aprendizagens (GEE, 2010)

Outro ponto que é necessário destacar como diferencial para a aprendizagem é o ambiente, a atmosfera, o lugar em que o sujeito se encontra enquanto joga. Os próprios sujeitos apontaram que, por estarem em um laboratório de pesquisa, sabendo que participariam de uma discussão pósjogo, passaram a prestar mais atenção nos detalhes da narrativa e dos elementos cênicos dos newsgames, se empenhando e se concentrando mais do que se estivessem jogando em casa, sozinhos, sem compromisso. Ou seja, é preciso também promover esse ambiente, em que o jogador se sinta à vontade para experimentar, fracassar e recomeçar, visando não apenas a diversão, mas também a aprendizagem.

Para encerrar, é importante apontar que muitas vezes, o newsgame da semana se constituía apenas na arena de encontro como um círculo subjetivo em torno do qual se desenvolvia a discussão. Ao falar e ouvir, contrapondo palavras, desenvolvia-se para cada um dos presentes uma compreensão ativa do tema e, somente assim, foi possível construir novos sentidos, desenvolver novas aprendizagens e produzir conhecimento. Enfim, o jogo em si é importante para a aprendizagem, não há dúvidas, mas o que fica para nós, professoras e pesquisadoras, é a importância do diálogo e da interação com o jogo e sobre o jogo. Esta sim é prenhe de infinitos sentidos e significados.

\section{REFERÊNCIAS}

ALVES, Lynn. Nativos digitais: games, comunidades e aprendizagens. In: MORAES, Ubirajara Carnevale de (org.). Tecnologia educacional e aprendizagem: o uso dos recursos digitais. São Paulo: Livro Pronto, 2007.

ALVES, Lynn. Relações entre os jogos digitais e aprendizagem: delineando percurso. In: Educação, Formação \& Tecnologias. v. 1 (2); p. 3-10, nov. 2008. Disponível em: http://eft.educom.pt/index.php/eft/article/view/58 . Acesso em: 10 dez. 2019.

ARRUDA, Eucídio Pimenta. Jogos digitais e aprendizagens: o jogo Age of Empires III desenvolve ideias e raciocínios históricos de jovens jogadores? 2019. Tese de Doutorado em Educação. Programa de Pós-Graduação em Educação: Conhecimento e Inclusão Social. Universidade Federal de Minas Gerais, Belo Horizonte, 2009.

BAKTHIN, Mikhail Volochínov. Marxismo e filosofia da linguagem. São Paulo: Hucitec, 2009.

BAKTHIN, Mikhail Volochínov. Questões de literatura e de estética (A teoria do romance). São Paulo: Ed. Unesp, 1993.

BOSGOST, Ian. Persuasive Games: The Expressive Power of Videogames. Massachusetts Institute of Technology, 2007a. Disponível em: https://users.hfgkarlsruhe.de/ arafinski/gamestudies/txt/Bogost PersuasiveGames.pdf. Acesso em: 10 dez. 2019. 
BROUGÈRE, Gilles. Jogo e educação. Porto Alegre: Artes Médicas, 1998.

BRUNO, Adriana R. A aprendizagem do educador: estratégias para a construção de uma didática online. 252 p. Tese de Doutorado. Programa de Pós-Graduação em Educação: Currículo. Pontifícia Universidade Católica de São Paulo, São Paulo, 2007.

CAILLOIS, Roger. Los juegos y los hombres: la máscara y el vértigo. México: Fondo de Cultura Econômica, 1994.

GEE, James Paul. Bons videojogos + boa aprendizagem: colectânea de ensaios sobre os videojogos, a aprendizagem e a literacia. Ramada, Portugal: Edições Pedagogo, 2010.

GIACOMO, Fred Di. A cobra vai fumar - Newsgame sobre a Segunda Guerra Mundial. Blog Newssgames da Superinteressante Digital. Publicado em 19 de abril de 2011. Acesso online indisponível.

HUIZINGA, Johan. Homo Ludens. O jogo como elemento da cultura. 4. ed. São Paulo: Perspectiva, 2005.

JOHNSON, Steven. Surpreendente! A televisão e os games nos tornam mais inteligentes. Rio de Janeiro: Elsevier, 2005.

LINDEROTH, Jonas. It is not hard, it just requires having no life - Computer games and the illusion of learning. Digital Kompetanse, 2009. v. 4, p. 4-19. Disponível em: https://www.academia.edu/5920536/_It_is_not_hard_it_just_requires_having_no_life_Comput er games and the illusion of learning 2009. Linderoth_J. Acesso em: 10 dez. 2019.

MURRAY, Janet H. Hamlet no Holodeck: o futuro da narrativa no ciberespaço. São Paulo: Itaú Cultural/Unesp, 2003.

PARK, Robert E. A notícia como forma de conhecimento. In: BERGER, C.; MAROCCO, B. (org.). A era glacial do jornalismo. v. 2. Porto Alegre/RS: Sulina, 2008, p. 51-70.

PRENSKY, Marc. Digital Game-based Learning. St. Paul, Minnesota: Paragon House Edition, 2007. E-book edition, 2013.

SANTAELLA, Lúcia, FEITOZA, Mirna. Mapa do jogo. A diversidade cultural dos games. São Paulo: Cengage Learning, 2009.

RIBEIRO, Janaína O. N. Newsgames e aprendizagem: possibilidade de construção de conhecimento a partir da interação com jogos digitais. 225 p. Tese de Doutorado. Programa de Pós-Graduação em Educação. Universidade Federal de Juiz de Fora. Juiz de Fora, Minas Gerais, 2016.

VIGOTSKY, Lev S. A brincadeira e seu papel no desenvolvimento psíquico da criança. Trad. Zoia Prestes. In: Revista Virtual de Gestão de Iniciativas Sociais. UFRJ: 2008. Disponível em: http://www.ltds.ufri.br/gis/anteriores/rvgis11.pdf. Acesso em: outubro de 2015.

VIGOTSKY, Lev S. A construção do pensamento e da linguagem. 2. ed. São Paulo: Martins Fontes, 2009.

VIGOTSKY, Lev S. A formação social da mente: o desenvolvimento dos processos psicológicos superiores. 7. ed. São Paulo: Martins Fontes, 2007. 
DOI: https://doi.org/10.12957/teias.2020.48637

\section{Informações das autoras}

Adriana Rocha Bruno

Professora da Universidade Federal do Estado do Rio de Janeiro (UNIRIO) e dos Programas de PósGraduação em Educação e em Gestão e Avaliação da Educação Pública da UFJF.

E-mail: arbruno2208@gmail.com

ORCID: https://orcid.org/0000-0002-5646-8919

Link Lattes: http://lattes.cnpq.br/9966072704077985

Janaína de Oliveira Nunes Ribeiro

Professora da Faculdade de Comunicação da Universidade Federal de Juiz de Fora.

E-mail: ninaolinunes@yahoo.com.br

ORCID: https://orcid.org/0000-0001-8690-8084

Link Lattes: http://lattes.cnpq.br/8582041950201449 